Document downloaded from:

http://hdl.handle.net/10251/149926

This paper must be cited as:

Zhang, W.; Albero-Sancho, J.; Xi, L.; Lange, KM.; García Gómez, H.; Wang, X.; Shalom, M. (2017). One-Pot Synthesis of nickel-modified carbon nitride layers toward efficient photoelectrochemical cells. ACS Applied Materials \& Interfaces. 9(38):32667-32677. https://doi.org/10.1021/acsami.7b08022

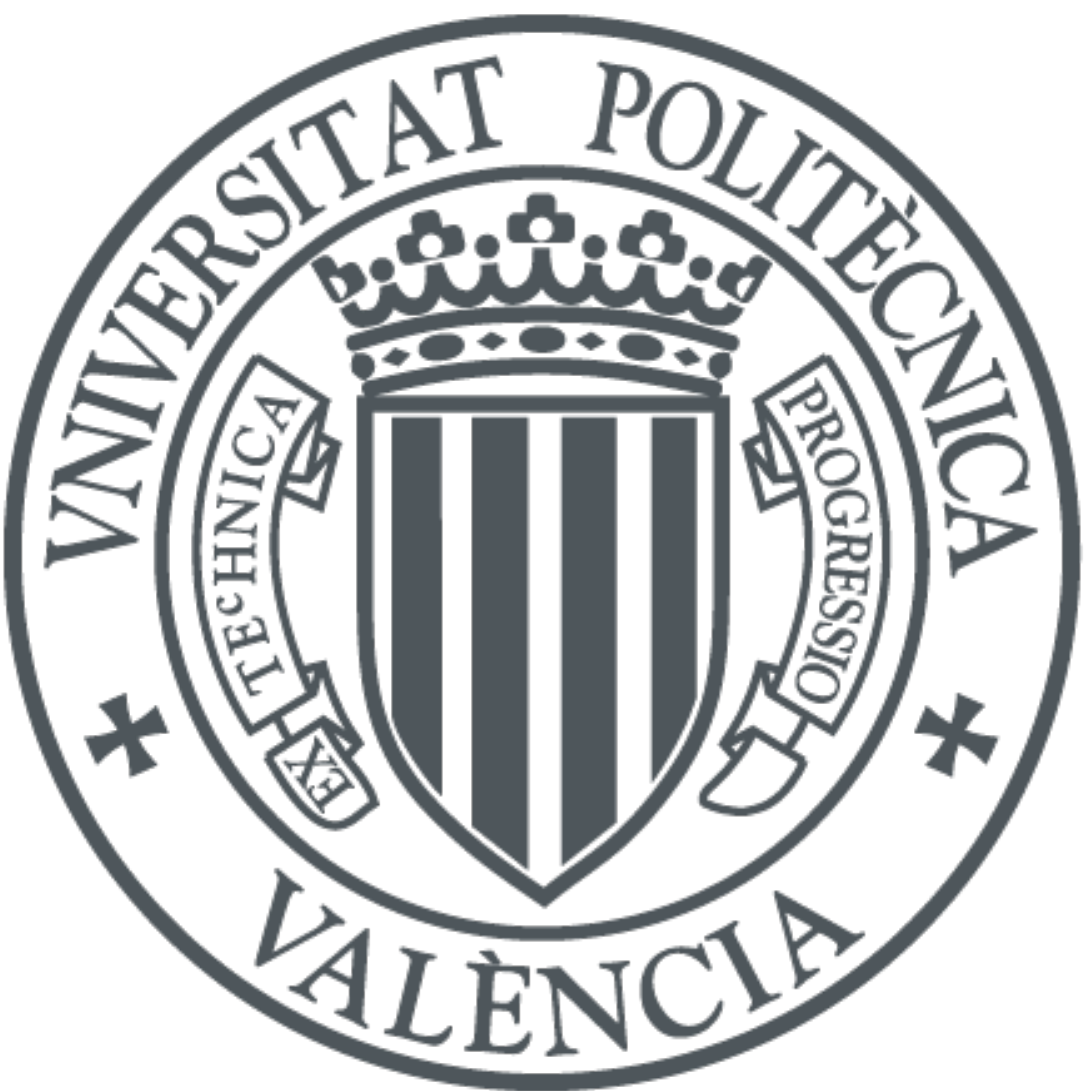

The final publication is available at

https://doi.org/10.1021/acsami.7b08022

Copyright American Chemical Society

Additional Information 


\section{One-pot Synthesis of Nickel-Modified Carbon}

\section{Nitride Layers Toward Efficient}

\section{Photoelectrochemical Cells}

Wenyao Zhang ${ }^{\dagger, \ddagger \pm}$, Josep Albero ${ }^{\ddagger}$, Lifei Xi $i^{ \pm}$,Kathrin M. Lange ${ }^{ \pm}$, Hermenegildo Garcia ${ }^{\ddagger}$, Xin Wang $^{\ddagger} *$, Menny Shalom ${ }^{\dagger *}$

${ }^{\dagger}$ Department of Chemistry, Ben Gurion University of the Negev, Beer-Sheva, 8410501, Israel.

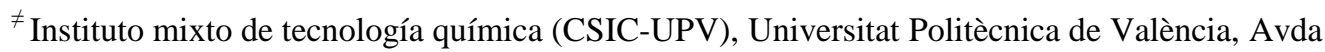
de los Narajos s/n, E-46022, Valencia, Spain.

${ }^{ \pm}$Department Operando Characterization of Solar Fuel Materials, Helmholtz-Zentrum Berlin für Materialien und Energie GmbH, Berlin, 12489, Germany.

${ }^{\ddagger}$ Key Laboratory of Soft Chemistry and Functional Materials, Nanjing University of Science and Technology, Ministry of Education, Nanjing 210094, China.

¥ Max-Planck Institute of Colloids and Interfaces, Department of Colloid Chemistry, Research Campus Golm, 14424 Potsdam, Germany

KEYWORDS: carbon nitride film, photoelectrochemical cells, nickel electrocatalyst, charge transfer, molten organic molecules 


\section{ABSTRACT}

A new method to significantly enhance the photoelectrochemical properties of phenyl-modified carbon nitride layers via the insertion of nickel ions into carbon nitride layers is reported. The nickel ions are embedded within the carbon nitride layers by manipulating the interaction of $\mathrm{Ni}$ ions and molten organic molecules at elevated temperature, prior their condensation. A detailed analysis of the chemical and photophysical properties suggests that the nickel ions dissolve in the molten molecules leading to the homogeneous distribution of nickel atoms within the carbon nitride layers. We found that the nickel atoms can alter the growth mechanism of carbon nitride layers resulting in extended light absorption, charge transfer properties and the total photoelectrochemical performance. The coordination of $\mathrm{Ni}$ ions in the most photoactive electrode exhibits an oxidation state of 2.8, as confirmed by soft X-ray absorption spectroscopy, which can be attributed to the most active nickel catalyst for water oxidation. Furthermore, important parameters as absorption coefficient, exciton life time and diffusion length were studied in-depth, providing substantial progress in our understanding of the photoelectrochemical properties of carbon nitride films. This work opens new opportunities for the growth of carbon nitride layers and similar materials on different surfaces and provides an important progress in our understanding of the photophysical and photoelectrochemical properties of carbon nitride layers toward their implantation in photo-electronic and other devices. 


\section{Introduction}

Photoelectrochemical splitting of water into oxygen and hydrogen has attracted considerable research interest because of the promise of becoming one of the leading technologies to address the intermittency and storage problem of solar energy. The heart of a photoelectrochemical cell (PEC) is based on a semiconductor that can absorb light and convert it to chemical energy by forming hydrogen and other carbon-based fuels. The search for a stable and low-cost semiconductor that can efficiently convert the absorbed light to into valuable fuels, is the main bottleneck for its plant-scale operation. ${ }^{1-2}$ Desired materials used in a practical PEC water splitting system should fulfill stringent requirements, as (i) good light-harvesting properties, (ii) suitable energy band position for water reduction and oxidation, and (iii) possess good charge separation properties under illumination. ${ }^{3}$ Up to date, most of the researched semiconductors are based on oxides as $\mathrm{TiO}_{2},{ }^{4} \mathrm{ZnO}^{5}$ and $\mathrm{WO}_{3}{ }^{6}$ due to their high stability under working conditions. However, their wide band gap strongly limits their light harvesting properties and the overall efficiency. Other oxides as $\mathrm{Fe}_{2} \mathrm{O}_{3}{ }^{7}$ and $\mathrm{BiVO}_{4}{ }^{8}$ have emerged as very promising light harvesting materials but high bulk recombination losses in $\mathrm{Fe}_{2} \mathrm{O}_{3}$ along with the scarcity and high-cost of bismuth strongly hinder their use in commercial devices. Varieties of other materials have been recently introduced as semiconductor materials for PECs - including, but not limited to, oxynitrides, ${ }^{9}$ metal chalcogenides, ${ }^{10}$ and carbon-based materials ${ }^{11}$ - and have shown promising results, but research on these materials is still in its beginning. Notwithstanding, despite great efforts and progress in this field, materials that can meet all the required criterions for semiconductor in PEC are still sought of.

Carbon-nitrogen based materials, ranging from graphitic carbon nitride to nitrogen doped carbon, have emerged recently as promising materials for energy-related applications as solar cells, fuel 
cells, photo and electrocatalysts thanks to their tunable molecular, electronic and catalytic properties as well as low-price, environmentally-friendly nature and stability under harsh condition. ${ }^{12-15}$ The alteration of their elements ratio and spatial organization lead to tunable electronic properties from wide band gap semiconductor (graphitic carbon nitride like materials, refer here as $\mathrm{CN}_{\mathrm{x}}$ ) that is commonly used for photocatalysis and optoelectronic applications, to semi-metals materials (nitrogen doped carbon) that show promising activity in electrochemical driven reactions. ${ }^{16}$ The traditional $\mathrm{CN}_{\mathrm{x}}$ synthesis entails the condensation of organic precursors containing carbon and nitrogen at elevated temperature. Intensive efforts have been done to optimize $\mathrm{CN}_{\mathrm{x}}$ photocatalytic properties, such as structure control $^{17}$ and protonation, ${ }^{18}$ heteroatoms (P, S, B, and $\mathrm{O}$ ) doping ${ }^{19-21}$, assembling heterojunctions with other semiconductors, ${ }^{22}$ loading with metal nanoparticles/ions ${ }^{23-24}$ and by copolymerization and preorganization of $\mathrm{CN}_{\mathrm{x}}$ monomers. ${ }^{25-26}$ However, the above-mentioned techniques are mostly researched to manipulated $\mathrm{CN}_{\mathrm{x}}$ properties as a powder while the modification of $\mathrm{CN}_{\mathrm{x}}$ layer is still at early stage. The main challenge lies in the need for high-quality and homogeneous $\mathrm{CN}_{\mathrm{x}}$ layers which form an intimate contact with the conductive substrates (e.g. FTO) ${ }^{27}$ Inspired by these facts, several preliminary attempts have been developed to fabricate $\mathrm{CN}_{\mathrm{x}}$ films on various substrates. Zhang et al. ${ }^{28}$ developed a sol process to effectively deposit $\mathrm{CN}_{\mathrm{x}}$ layers on fluorinedoped tin oxide (FTO)-coated glass. Bian et al. ${ }^{29}$ performed the growth of uniform $\mathrm{CN}_{\mathrm{x}}$ films by vapor-transport deposition. Our group introduced a liquid-mediated growth approach for continuous $\mathrm{CN}_{\mathrm{x}}$ films on various substrates and demonstrated the strength of this deposition method by employing these films in solar cells and organic light emitting diodes. ${ }^{30}$ However, despite the continuous progress, several factors as low harvesting properties emanates from the wide band gap of carbon nitride $(\sim 2.7 \mathrm{eV})$, low charge mobility and separation and insufficient 
hole removal as well as the lack of knowledge about the photophysical and electronic properties in CNs layers still inhibit the solar-to-energy conversion efficiency in PEC. A general approach to improving hole extraction and oxygen production in PEC is by using suitable oxygen evolution reaction (OER) catalyst coupled to the light harvesting semiconductor. ${ }^{8,} 31$ Under working conditions, the holes are transferred to the OER catalyst which facilitates the thermodynamic barrier for oxygen production. Several transition metals have been used to modify $\mathrm{CN}_{\mathrm{x}}$ catalytic properties. ${ }^{32-33}$ However, Ni-based materials have been considered to be amid the most efficient and stable OER catalysts for an alkaline solution. ${ }^{34}$ Moreover, nickel ions are known to coordinate well with pyridine-like nitrogen group in $\mathrm{CN}_{\mathrm{x}}{ }^{35}$ The latter can direct the growth of the materials and their final elements composition, projecting on their photophysical, chemical, electronic and catalytic properties. However, best to our knowledge, a successful integration of OER catalysts with $\mathrm{CN}_{\mathrm{x}}$ layers and their effect on the $\mathrm{CN}_{\mathrm{x}}$ layers growth and final charge transfer, optical and catalytic properties have never been studied.

Herein, we reported a liquid-mediated pathway to directly synthesize nickel embedded phenylmodified carbon nitride $\left(\mathrm{Ni}-\mathrm{CN}_{\mathrm{x}}\right)$ layers onto FTO glass, serving as active photoanodes in water splitting-PEC. The deposition of Ni-CNx was acquired by one-pot synthesis of cyanuric acid and 2,4-diamino-6-phenyl-1,3,5-triazine supramolecular aggregates with various ratios of $\mathrm{Ni}$ chloride salt, ranging from 1 to $10 \%$ molar ratio. The role of the $\mathrm{Ni}$ ions on the $\mathrm{CN}_{\mathrm{x}}$ materials growth and their photophysical, chemical and catalytic properties were comprehensively studied by X-ray photoelectron spectroscopy (XPS), Scanning electron microscopy (SEM) and Ultraviolet-visible (UV-Vis) absorption as well as by X-ray absorption spectroscopy (XAS) and Transient absorption spectroscopy (TAS). The photoelectrochemical properties were investigated by 
researching the activity for oxygen production in alkaline media under AM 1.5G along with the incident photon-to-current efficiency (IPCE) at $1.23 \mathrm{~V}$ vs. reversible hydrogen electrode (RHE).

\section{Experimental Section}

Deposition of $C N_{x}$ and $\mathrm{Ni}$ embedded $C N_{x}$ films on FTO glass. All the chemicals were purchased from Sigma-Aldrich and used without further purification. FTO glasses were washed with detergent to remove the pollutants and then sonicated in acetone for $30 \mathrm{~min}$. Afterwards they were rinsed with ethanol and dried using nitrogen flow. Specifically, cyanuric acid (C) and 2,4diamino-6-phenyl-1,3,5-triazine (Mp) with the molar ratio of 1:1 were mixed in $50 \mathrm{~mL}$ deionized water. After shaken overnight, separated by centrifugation and vacuum dried, CMp supramolecular was obtained. Then different nickel chlorides amount was weighted and mixed with CMp powder by fine grinding using a mortar. The mixtures were transferred into ceramic crucibles, totally covering the FTO substrate on the bottom. The crucible was capped with a ceramic lid and heated at a rate of $2.3^{\circ} \mathrm{C} \min ^{-1}$ up to $550{ }^{\circ} \mathrm{C}$, and kept at this temperature for $4 \mathrm{~h}$ under a constant nitrogen flow. After cooling to room temperature the substrate was cleaned by sonication in water to remove the residual aggregates on the surface.

Materials Characterization. Scanning electron microscopy (SEM) images, energy dispersive Xray (EDX) spectroscopy, and elemental mapping were performed on JSM-7500F (JEOL) equipped with an Oxford Instruments X-MAX80 $\mathrm{mm}^{2}$ detector. Transmission electron microscopy (TEM) images were recorded on a JEOL JEM-2100 microscope. X-ray photoelectron spectra (XPS) were recorded using an RBD upgraded PHI-5000C ESCA system (Perkin Elmer) with $\mathrm{Al} \mathrm{K} \alpha$ radiation $(\mathrm{h} v=1486.6 \mathrm{eV})$, and the peaks were calibrated by the $\mathrm{C} 1 \mathrm{~s}$ at $284.6 \mathrm{eV}$. The sputtering rate for recording the XPS depth profile was $2 \mathrm{~nm}$ min $^{-1}$. X-ray 
absorption (XA) spectra recorded in total electron yield (TEY) mode were obtained in the LiXEdrom 2.0 endstation at the U56-2-PGM2 beamline at Bessy II. From the C and N K-edge spectra, the background was subtracted and their intensities were normalized to the spectral feature at $285.1 \mathrm{eV}$ and $399.2 \mathrm{eV}$, respectively. From the Ni L-edge spectra, the background was subtracted and their intensity was normalized by the integrated area under the peaks. The energy resolution was $190 \mathrm{meV}$ at $837 \mathrm{eV}$. Energy calibration of the Ni spectra was performed with the $850.6 \mathrm{eV}$ peak using a $\mathrm{NiO}$ powder spectrum. The Ni spectra were fitted using the linear combination method. The percentage values were calculated according to the linear fitting algorithm as below:

Fitted spectrum $=a^{*} N i\left(^{1+}\right)+b^{*} \operatorname{LSNi}\left({ }^{2+}\right)+c^{*} H S N i\left({ }^{2+}\right)+d^{*} L S N i\left({ }^{3+}\right)$

Percentage of each nickel oxide is obtained by Ni $\left({ }^{1+}\right)=a /(a+b+c+d), L S N i\left(^{2+}\right)=b /(a+$ $b+c+d)$, etc.

The optical characteristics of the films were analyzed by Ultraviolet-visible (UV-vis) spectroscopy, which was performed using a Cary 5000 spectrophotometer equipped with an integrating sphere. The absorption coefficient $(\alpha)$ was determined by:

$\alpha=\frac{-\ln \left(10^{- \text {absorbance }}\right)}{z} \quad$ Equation (1)

where $z$ is the film thickness.

PEC Measurement. Photoelectrochemical tests were conducted in a three electrode configuration (Potentiostat EG\&G PAR 283). The $\mathrm{CN}_{\mathrm{x}}$ or Ni-CN $\mathrm{CN}_{\mathrm{x}}$ films with an illumination area of $0.283 \mathrm{~cm}^{2}$, a Pt wire and an $\mathrm{Ag} / \mathrm{AgCl}$ electrode (XR300, saturated $\mathrm{KCl}$ and $\mathrm{AgCl}$ solution, Radiometer Analytical) was served as the working, counter and reference electrodes, respectively. Simulated 
AM 1.5 solar illumination $\left(100 \mathrm{~mW} \mathrm{~cm}^{-2}\right)$ was achieved with a Newport Sol3A Class AAA solar simulator (94023A-SR3 type) as a light source. The electrolyte was $0.1 \mathrm{M}$ potassium hydroxide (KOH) solution, $\mathrm{pH} \sim 13$. For the incident photon-to-current efficiency (IPCE) measurements: Monochromatic photocurrents were measured with a $300 \mathrm{~W}$ Xenon lamp (Oriel, model 6259) coupled into a grating monochromator (Acton Spectra Pro 2155). Long pass filters (3 mm thick, Schott) were used to block any second-order diffracted light. The monochromatic light intensities were measured with a calibrated photodiode (PD300UV diode read by a Nova II controller, Ophir Photonics). IPCE values were calculated using the following equation:

$\operatorname{IPCE}(\lambda)=\frac{1240 j_{p}(\lambda)}{\lambda E_{\lambda}(\lambda)}$ Equation (2)

where $\mathrm{j}_{\mathrm{p}}(\lambda)$ is the steady-state photocurrent density at a specific wavelength $\left(\mathrm{mA} / \mathrm{cm}^{2}\right)$ and $\mathrm{E}_{\lambda}(\lambda)$ is the incident light power density $\left(\mathrm{mW} / \mathrm{cm}^{2}\right)$ for each wavelength, $\lambda(\mathrm{nm})$.

Mott-Schottky $\left(1 / \mathrm{C}^{2}\right.$ vs V) measurements were carried out using the same system in $0.2 \mathrm{M}$ $\mathrm{Na}_{2} \mathrm{SO}_{4}$ aqueous solution as the electrolyte at a frequency of $2 \mathrm{kHz}$ recorded by a Gamry Reference 3000 potentiostat (Gamry Instruments, US). Transient absorption spectra were recorded using a home-built system constituted by a Q switched Nd: YAG laser (Quantel Brilliant, 7 ns fwhm) coupled to a photodetector based on a Si photodiode connected to a Tektronic TDS-2001C digitizer. The probe is supplied by $200 \mathrm{~W}$ Halogen lamp filtered with two monochromators. The laser excitation was fixed at $1 \mathrm{~Hz}$ using and $532 \mathrm{~nm}$ excitation wavelength. The films were placed in a sealed quartz cuvette and purged for $15 \mathrm{~min}$. with Ar or directly placed in the cuvette in air conditions. For the $\mathrm{MeOH}$ saturated atmosphere, the samples were purged for 15 in Ar and sealed. After that, $40 \mu \mathrm{l}$ of $\mathrm{MeOH}$ was added to the cuvette and allowed to evaporate. 


\section{Results and discussion}

The growth of thin film on FTO (fluorine-doped tin oxide) substrate was made according to our previous report with small modifications ${ }^{30}$. Briefly, cyanuric acid (C) and 2,4-diamino-6-phenyl1,3,5-triazine (Mp) with a molar ratio of 1:1 was mixed in water and a supramolecular complex of hydrogen-bonded CMp were formed after shaking. The CMp was ground with different amount of nickel chloride and then transferred into a crucible, totally covering the substrate. The system was heated to $550{ }^{\circ} \mathrm{C}$ for $4 \mathrm{~h}$ under nitrogen atmosphere. Scanning electron microscopy (SEM) images of phenyl-modified carbon nitride nanosheets $\left(\mathrm{CN}_{\mathrm{x}}\right)$ and nickel-embedded phenyl-modified carbon nitride nanosheets $\left(\mathrm{Ni}-\mathrm{CN}_{\mathrm{x}}\right)$ on FTO show a uniform and ordered porous structure (Figure 1). In all cases, the morphology of the films possesses an interconnected porous network with pores size of several micrometers. With increasing the nickel content, the $\mathrm{Ni}-\mathrm{CN}_{\mathrm{x}}$ strands tend to grow into larger sheets, filling the pores with a continuous layer. These changes in morphology could directly influence their electronic structures (e.g. conductivity and charge separation) via the introduction of the better network for charge flow. Moreover, the thickness of the layers, an important factor in PEC, is altered upon Ni introduction. For example, the thickness of the $3 \%$ and $5 \% \mathrm{Ni}-\mathrm{CN}_{\mathrm{x}}$ layers is lower ( 550 and $500 \mathrm{~nm}$, respectively) compared to pristine $\mathrm{CN}_{\mathrm{x}}(\sim 650 \mathrm{~nm})$ layers (Figure S1 and S2). 

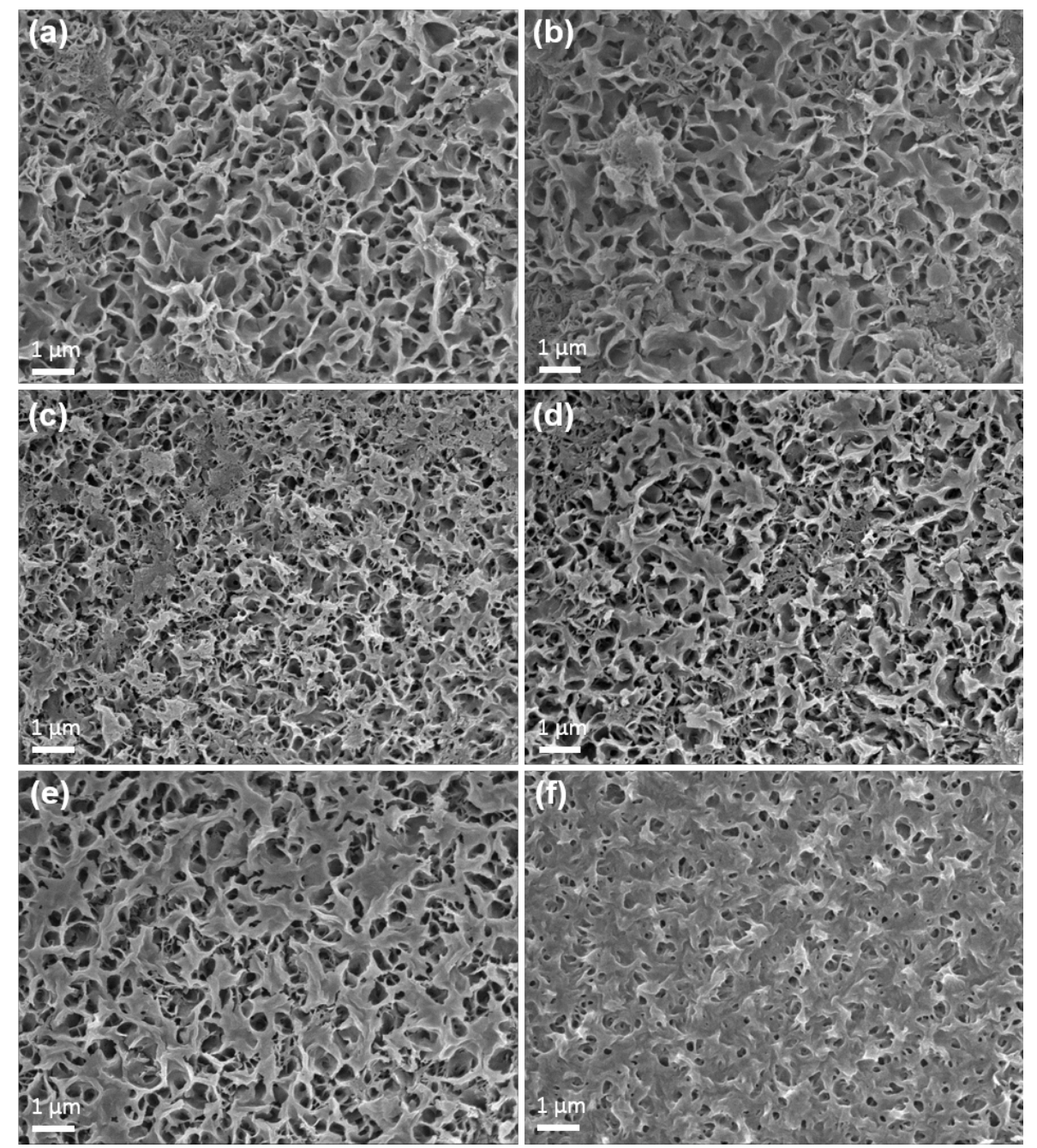

Figure 1. SEM images of (a) $\mathrm{CN}_{\mathrm{x}}$, (b) $0.1 \% \mathrm{Ni}-\mathrm{CN}_{\mathrm{x}}$, (c) $0.5 \% \mathrm{Ni}-\mathrm{CN}_{\mathrm{x}}$, (d) $1 \% \mathrm{Ni}-\mathrm{CN}_{\mathrm{x}}$, (e) $3 \%$ $\mathrm{Ni}-\mathrm{CN}_{\mathrm{x}}$, (f) $5 \% \mathrm{Ni}-\mathrm{CN}_{\mathrm{X}}$. 

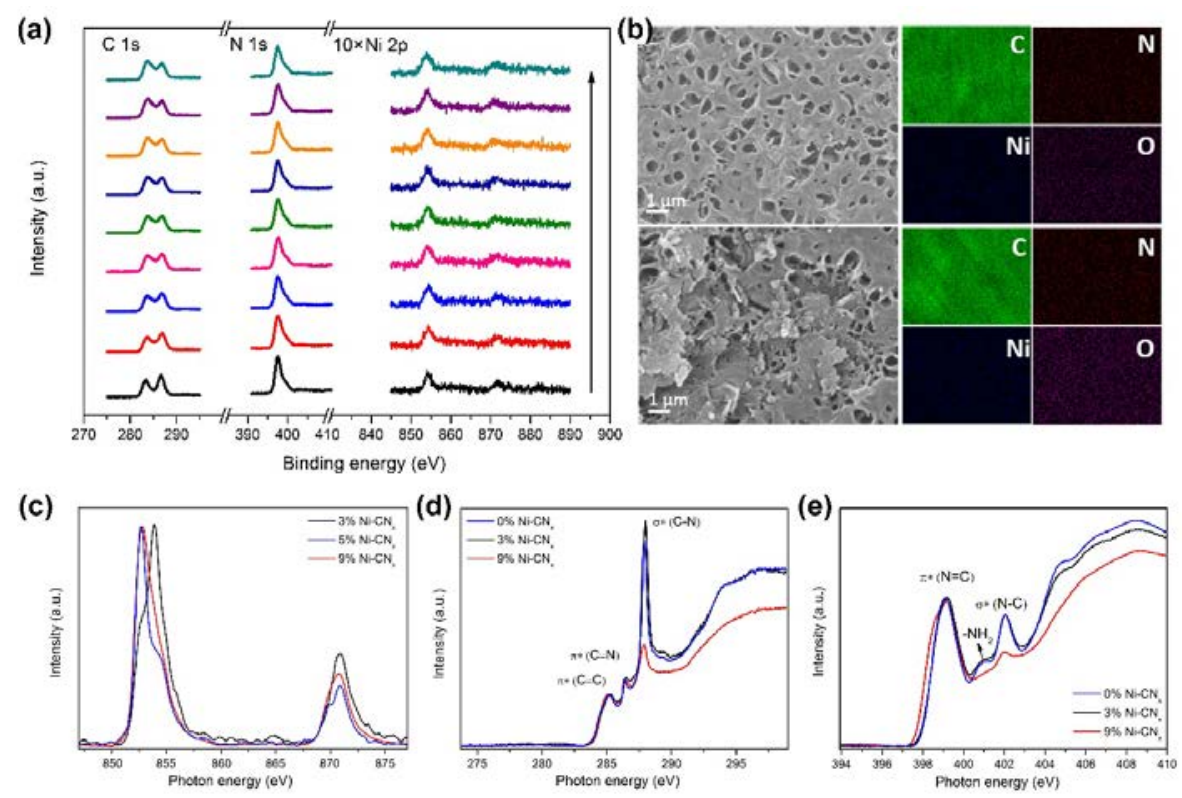

Figure 2. (a) XPS depth profile of $\mathrm{C} 1 \mathrm{~s}, \mathrm{~N} 1 \mathrm{~s}, \mathrm{Ni} 2 \mathrm{p}$ in $3 \% \mathrm{Ni} \mathrm{CN}_{\mathrm{x}}$; (b) SEM images and EDX mapping of 3\% $\mathrm{Ni} \mathrm{CN}_{\mathrm{x}}$, surface (up), inside (down); XA spectra of (c) Ni L-edge, (d) C K-edge and (e) N K-edge of the pristine $\mathrm{CN}_{\mathrm{x}}$ and Ni modified $\mathrm{CN}_{\mathrm{x}}$ films.

XPS measurements were performed to determine the evolution of chemical states of $\mathrm{C}, \mathrm{N}$, and $\mathrm{Ni}$ in the Ni-CN layers (Figure S3). The high-resolution C 1s spectra of $\mathrm{CN}_{\mathrm{x}}$ film and the modified $\mathrm{CN}_{\mathrm{x}}$ film provide more detailed information of structural changes induced by the $\mathrm{Ni}$ ions. For the pristine $\mathrm{CN}_{\mathrm{x}}$, two distinguished peaks, centered at $284.6 \mathrm{eV}$ and $287.8 \mathrm{eV}$, ascribed to $\mathrm{C}=\mathrm{C}$ and $\mathrm{C}=\mathrm{N}-\mathrm{C}$ coordination, respectively, were recorded. For $\mathrm{Ni}-\mathrm{CN}_{\mathrm{x}}$, a gradual decrease in the intensity of the $\mathrm{C}=\mathrm{N}-\mathrm{C}$ peak with increasing nickel content can be observed, indicating a deviation from the optimal tri-s-triazine structure. This might occur due to the good solubility of $\mathrm{Ni}$ ions in the liquid monomers, prior the CNx polymerization. During heating, the solid CMp precursor turns into a liquid at around $400{ }^{\circ} \mathrm{C}$ and the nickel chloride is dissolved and diffuses to 
form a homogeneous mixture. Subsequently, nickel ions are able to coordinate with either the condensed heptazinic- $\mathrm{N}$ or uncondensed $-\mathrm{NH}_{2}$, which hinder the polymeric condensation but facilitates the deamination process. Further increase of the calcination temperature results in the formation of nickel embedded into a low-crystalline carbon-nitrogen scaffold.

In order to study the chemical composition of the obtained films and to gain better understanding about the Ni effect on the photophysical, chemical, and catalytic properties, XPS depth profile of each element and energy-dispersive X-ray spectra (EDS) mapping measurements were performed for a representative 3\% Ni-CN ${ }_{\mathrm{x}}$ (Figure 2). We choose to focus on $3 \% \mathrm{Ni}-\mathrm{CN}_{\mathrm{x}}$ due to its high photoelectrochemical activity as shown later. The chemical composition of the film surface shows almost no difference compared to the inner part, except small changes in the carbon coordination and amount. From the XPS depth profile studies of $\mathrm{C} 1 \mathrm{~s}$, the portion of $\mathrm{C}=\mathrm{C}$ coordination has greatly enhanced from the surface to the substrate, suggesting a gradient of the phenyl groups (from CMp precursor) across the layer. As the band gap and corresponding lightharvesting properties are directly derived from the $\mathrm{C} / \mathrm{N}$ ratio (i.e. higher $\mathrm{C} / \mathrm{N}$ ratio leads to a semiconductor with lower band gap), the carbon gradient can create an energy level cascade, which is beneficial for the excited electrons to transfer from the interface to the FTO substrate. This will be further discussed in the photoelectrochemistry part. As for the elementary $\mathrm{N}$ and $\mathrm{Ni}$, a series of XPS depth profiles indicate negligible changes in terms of position and content, demonstrating that $\mathrm{Ni}$ ions are homogeneously intercalated into the crystal structure of $\mathrm{CN}_{\mathrm{x}}$ as well as that the carbon increase along the layers originates from better phenyl incorporation in the structure. The latter indicates that during heating, $\mathrm{Ni}$ ions are fully dissolved in the liquidphase of the organic molecules. Furthermore, EDS mappings of the surface and the bulk of the $3 \% \mathrm{Ni}-\mathrm{CN}_{\mathrm{x}}$ film are presented in Figure $2 \mathrm{~b}$, confirming that each element is well dispersed 
within the film. Based on the above-mentioned results we can safely assume the successful fabrication of nickel embedded into phenyl-modified carbon nitride layers on FTO substrate.

Soft X-ray absorption spectroscopy (XAS) is a powerful element-specific tool to probe the partially occupied $\mathrm{Ni}$ d-orbitals and to reveal detailed information about oxidation state contributions, spin-states, and charge transfer. ${ }^{36-37}$ The information of the percentage of different $\mathrm{Ni}$ species in the $\mathrm{Ni}-\mathrm{CN}_{\mathrm{x}}$ layers, as well as the average oxidation state, can be obtained by the linear combination fitting method. ${ }^{38-39}$ Figure 2c shows the XA spectra of Ni-CN $\mathrm{X}_{\mathrm{x}}$ films with different Ni content. The XA spectra of Ni L-edge from the Ni modified $\mathrm{CN}_{\mathrm{x}}$ films have two characteristic broad multiplet structures, $\mathrm{L}_{3}$ and $\mathrm{L}_{2}$ that are separated by spin-orbit coupling. The shape of the spectra related to the 3d orbital occupation changes with different Ni loading. For detailed analysis previously published nickel compounds reference spectra ${ }^{40}$ of $\mathrm{Ni}\left({ }^{1+}\right)$, low spin (LS) $\mathrm{Ni}\left({ }^{2+}\right)$, high spin (HS) $\mathrm{Ni}\left({ }^{2+}\right)$, LS $\mathrm{Ni}\left({ }^{3+}\right)$ are also shown in Figure S4. We assign the spectra features located at 852.2, 852.9, 853.5 and $853.9 \mathrm{eV}$ to the contributions of Ni $\left({ }^{1+}\right)$, low spin (LS) $\mathrm{Ni}\left({ }^{2+}\right)$, high spin (HS) $\mathrm{Ni}\left({ }^{2+}\right)$, LS $\mathrm{Ni}\left({ }^{3+}\right)$ oxidation states, respectively. In order to get detailed electronic and structural information, a linear combination fitting of the Ni L-edge spectra of different $\mathrm{Ni}$ concentrations was carried out. All spectra and the respectively fitted spectra are shown in Figure S4. Table 1 shows the complete fitting results for the Ni L-edge spectra of our Ni modified $\mathrm{CN}_{\mathrm{x}}$ film under different loadings. It was found that a $3 \% \mathrm{Ni}$ modified $\mathrm{CN}_{\mathrm{X}}$ film consists of $1 \% \mathrm{Ni}\left({ }^{1+}\right), \sim 12 \%$ of LS Ni $\left({ }^{2+}\right), 3 \%$ of HS Ni $\left({ }^{2+}\right)$ and $84 \%$ of LS Ni $\left({ }^{3+}\right)$ which indicates that the electronic structure of the $3 \% \mathrm{Ni}$ modified $\mathrm{CN}_{\mathrm{x}}$ is dominated by LS Ni $\left({ }^{3+}\right)$. From these results an average oxidation state of $\sim 2.8$ was determined. Increasing the $\mathrm{Ni}$ loading leads to a reduction of the average oxidation state of the Ni modified $\mathrm{CN}_{\mathrm{x}}$ film. For example, 5 and $9 \% \mathrm{Ni}$ modified $\mathrm{CN}_{\mathrm{x}}$ have the average oxidation states of 2.2 and 2.3. The high 
oxidation state of all the Ni further supports our postulation that nickel ions are fully dispersed in the $\mathrm{CN}_{\mathrm{x}}$ matrix. The $\mathrm{Ni}$ oxidation state in $3 \% \mathrm{Ni}-\mathrm{CN}_{\mathrm{x}}$ is similar to $\mathrm{NiOOH}$ specie which is known as highly active OER electrocatalyst.

Table 1. Summary of linear combination fitting of Ni modified $\mathrm{CN}_{\mathrm{x}}$ films.

\begin{tabular}{llllll}
\hline Ni content & $\mathrm{Ni}^{1+}(\mathbf{\%})$ & $\mathrm{LS} \mathrm{Ni}^{2+} \mathbf{( \% )}$ & $\mathrm{HS} \mathrm{Ni}^{2+} \mathbf{( \% )}$ & $\mathrm{LS} \mathrm{Ni}^{3+} \mathbf{( \% )}$ & Ave. oxid. state \\
\hline $3 \%$ & 1 & 12 & 3 & 85 & 2.8 \\
$5 \%$ & 1 & 0 & 83 & 16 & 2.2 \\
$9 \%$ & 1 & 6 & 67 & 27 & 2.3 \\
\hline
\end{tabular}

Note: LS: low spin, HS: high spin. $\mathrm{Ni}^{1+}:\left[\mathrm{PhTt}^{\mathrm{tBu}}\right] \mathrm{Ni}^{1+} \mathrm{CO}, \mathrm{LS} \mathrm{Ni}{ }^{2+}:\left(\mathrm{Ph}_{4} \mathrm{As}\right)_{2} \mathrm{Ni}^{2+}\left[\mathrm{S}_{2} \mathrm{C}_{2}\left(\mathrm{CF}_{3}\right)_{2}\right], \mathrm{HS}^{\mathrm{Ni}}{ }^{2+}: \mathrm{NiO}^{\mathrm{LS}} \mathrm{Ni}^{3+}$ : macrocyclic tetraamide $\mathrm{Ni}^{3+}$ complex, $\mathrm{PhTt}^{\mathrm{tBu}}=$ phenyltris((tertbuthylthio)methyl)borate. ${ }^{40}$

$\mathrm{C}$ and $\mathrm{N}$ K-edge spectra of the pristine $\mathrm{CN}_{\mathrm{x}}$ and $\mathrm{Ni}$ modified $\mathrm{CN}_{\mathrm{x}}$ films are also studied (Figure 2d and 2e). In the C K-edge spectra, an absorption peak located at $285.1 \mathrm{eV}$ and a shoulder peak at $284.5 \mathrm{eV}$ is assigned to a $\pi^{*}(\mathrm{C}=\mathrm{C})$ resonance of aromatic carbon species, a peak at $286.1 \mathrm{eV}$ is assigned to a $\pi^{*}(\mathrm{C}=\mathrm{N})$ transition while a peak at $287.5 \mathrm{eV}$ is assigned to an $\sigma^{*}(\mathrm{C}-\mathrm{N})$ transition. The broad absorption band above $293 \mathrm{eV}$ is characteristic for the pyridine-like structure of carbon nitride. It can be seen that with increasing the Ni content from 0 to 3\%, the $\mathrm{C}$ K-edge spectrum intensity slightly decreases. When further increasing the Ni loading to $9 \%$, the C K-edge spectrum shows a significant decrease in intensity. Considering that the spectra were intensity normalized to the feature at $285 \mathrm{eV}$ the spectral changes can be correlated to a relative decrease in the number $\mathrm{C}-\mathrm{N}$ bonds compared to $\mathrm{C}=\mathrm{N}$ and $\mathrm{C}=\mathrm{C}$ bonds induced by $\mathrm{Ni}$ 
incorporation. The N K-edge spectra are in good accordance with the C K-edge spectra and can be interpreted in a similar way. For example, peaks at 399.2 and $402.0 \mathrm{eV}$ are assigned to $\pi^{*}$ $(\mathrm{C}=\mathrm{N})$ and $\sigma^{*}(\mathrm{C}-\mathrm{N})$ transitions while a weak peak at $400.9 \mathrm{eV}$ is assigned to the amino type species $\left(-\mathrm{NH}_{2}\right){ }^{41}$ Also here a relative decrease of C-N species is observed. In the $\mathrm{N}$ K-edge spectra, a shoulder at $398.2 \mathrm{eV}$ appeared in $9 \% \mathrm{Ni}$ modified $\mathrm{CN}_{\mathrm{x}}$ film implies a disordered $\mathrm{CN}_{\mathrm{x}}$ network due to Ni incorporation.
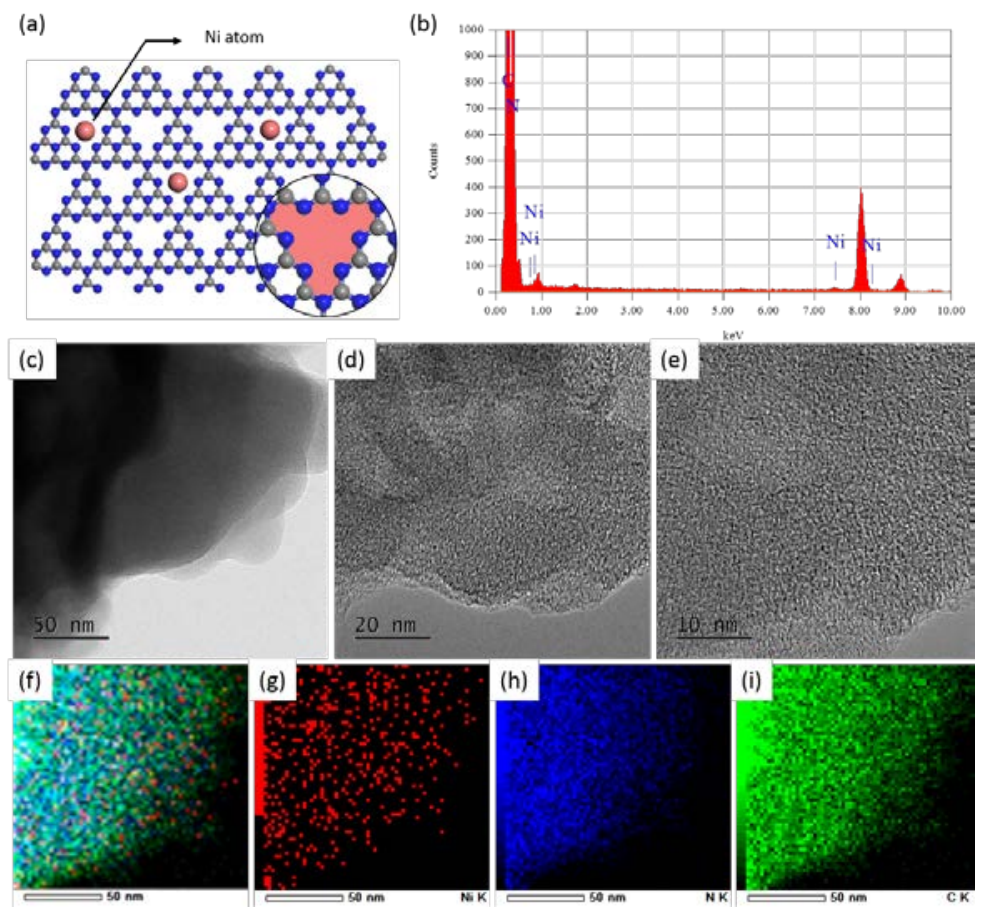

Figure 3. (a) Illustration of the structure of the materials, (b) energy dispersive X-ray spectrum of $3 \% \mathrm{Ni}-\mathrm{CN}_{\mathrm{x}}$, (c-e) Typical TEM images of $3 \% \mathrm{Ni}-\mathrm{CN}_{\mathrm{x}}$, (f-i) the corresponding elemental mapping images of all elements, $\mathrm{Ni}, \mathrm{N}$, and $\mathrm{C}$, respectively. 
Figure S5 shows the TEM images of $\mathrm{CN}_{\mathrm{x}}$ and different $\mathrm{Ni}-\mathrm{CN}_{\mathrm{X}}$ demonstrating that Ni species are fully embedded into the CN layer. It is noteworthy that we couldn't observe metal aggregates below $10 \%$ of $\mathrm{Ni}$. The latter suggests that nickel ions are able to embed within the $\mathrm{CN}_{\mathrm{x}}$ structure instead of precipitate as nanoparticles. Figure 3 shows high magnification TEM images of 3\% $\mathrm{Ni}-\mathrm{CN}_{\mathrm{x}}$ and the corresponding energy-dispersive X-ray spectrometry (EDS) elemental mapping results. Limited by the resolution of our microscope, we cannot detect nanoparticles with less than $0.6 \mathrm{~nm}$ size. However, the corresponding EDS spectrum confirms successful incorporation of nickel with a distinguishable nickel signal, and the EDS elements mapping reveals that Ni, C, $\mathrm{N}$ are homogenously dispersed throughout the samples. Considering the van der Waals diameter of a single nickel atom, it is reasonable to assume that nickel atoms are distributed and embedded into the vacancies of tri-s-triazine subunits (Figure S6).

Another proof for the $\mathrm{Ni}$ ions coordination to the $\mathrm{CN}_{\mathrm{x}}$ matrix is given by $\mathrm{XRD}$ patterns (Figure S7a). The strong interplanar stacking peak of connected tri-s-triazine around $27.5^{\circ}$ is slightly shifted toward lower angle upon the increase of nickel, speaking for the higher layer distance derived from an incorporation of nickel ions into the $\mathrm{CN}_{\mathrm{X}}$ sheets. In addition, the increase of nickel amount leads to a decrease in the crystallinity of $\mathrm{Ni}-\mathrm{CN}_{\mathrm{x}}$, but the absence in the XRD patterns of other nickel species such as nickel, nickel chlorides, nickel nitrides, nickel carbides and nickel oxides strongly suggest that $\mathrm{Ni}$ ions are effectively embedded in the g-CN layers. Fourier transform infrared spectroscopy (FT-IR) reveals that the original graphitic C-N network remains mostly unchanged after incorporating nickel (Figure S7b). The typical breathing vibration mode at $810 \mathrm{~cm}^{-1}$ for tri-s-triazine subunits, as well as skeletal vibrations at $1200-1600$ $\mathrm{cm}^{-1}$ for aromatic C-N heterocycles, ${ }^{28,42}$ can be found in all the materials. Therefore, we can assume that the $\mathrm{Ni}$ incorporation does not break the $\mathrm{C}-\mathrm{N}$ lattice within the $\mathrm{CN}_{\mathrm{x}}$ films. Elemental 
analysis (Figure S8) shows that the increase of nickel content leads to larger carbon/nitrogen $(\mathrm{C} / \mathrm{N})$ ratio, presumably due to a large extend of deamination, facilitated by nickel chloride as Lewis acid and by the better phenyl group incorporation into the $\mathrm{CN}_{\mathrm{x}}$ networks (Table S1 and

\section{Table S2).}
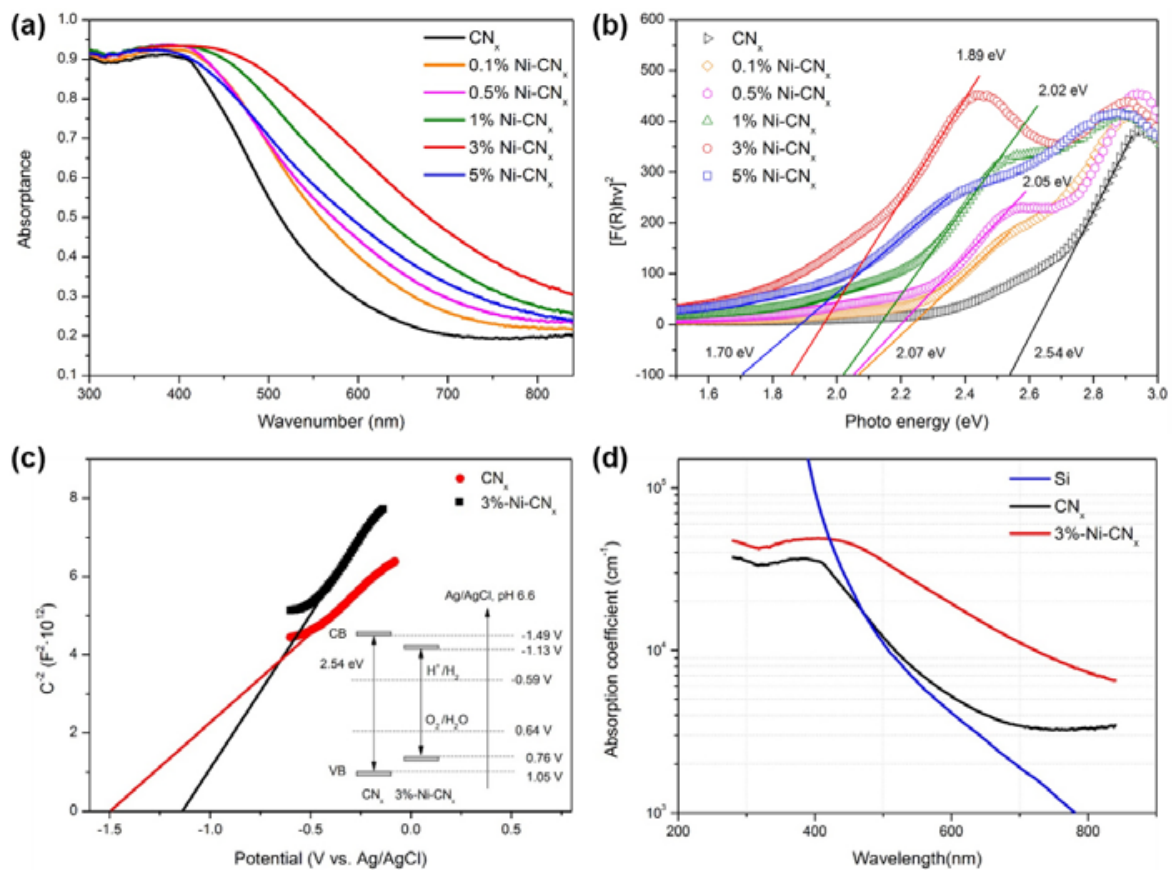

Figure 4. (a) UV-vis absorbance spectrum, (b) Kubelka-Munk function versus energy plots for $\mathrm{CN}_{\mathrm{x}}$ films deposited with different nickel content; (c) Mott-Schottky plots and band structure (inset; CB: conduction band, VB: valence band) of $\mathrm{CN}_{\mathrm{x}}$ and $3 \% \mathrm{Ni}-\mathrm{CN}_{\mathrm{x}}$ films (d) Absorption coefficient of $\mathrm{Si}, \mathrm{CN}_{\mathrm{x}}$ and $3 \% \mathrm{Ni}-\mathrm{CN}_{\mathrm{x}}$ films, Plot was derived from transflectance measurements under front side illumination.

UV-vis measurements were performed to determine the optical properties of the all the Ni-CN films compared to the pristine one. Figure 4a shows the absorption spectra of different $\mathrm{CN}_{\mathrm{x}}$ 
based films, measured with an integrating sphere to distinguish the absorbance from reflective light scattering. The Ni insertion leads to a remarkable absorption red-shift compared to the absorption spectra of pristine $\mathrm{CN}_{\mathrm{x}}$, further indicating the modification of the electronic structure of CNx by nickel incorporation. Noticeably, the optical density of $5 \% \mathrm{Ni}-\mathrm{CN}_{\mathrm{x}}$ is lower; probably due to inner stress caused by nickel, resulting in a sheer thickness decline. The bandgap of $\mathrm{CN}_{\mathrm{x}}$ layers were calculated according to Kubelka-Munk function (Figure 4b), which points to a direct band gap for all the materials. Mott-Schottky analysis was preformed to determine the flat band potential of the Ni-CN ${ }_{x}$ and their suitability for water splitting-PEC. Figure 4c discloses a typical n-type behavior of both $\mathrm{CN}_{\mathrm{x}}$ and $3 \% \mathrm{Ni}-\mathrm{CN}_{\mathrm{x}}$. The derived flat-band potentials for $\mathrm{CN}_{\mathrm{x}}$ and $3 \%$ $\mathrm{Ni}-\mathrm{CN}_{\mathrm{x}}$ are $-1.49 \mathrm{~V}$ and $-1.13 \mathrm{~V}$ vs. $\mathrm{Ag} / \mathrm{AgCl}$, respectively, indicating their ability to oxidize water $\left(\mathrm{O}_{2} / \mathrm{H}_{2} \mathrm{O}: 0.64 \mathrm{~V}\right.$ vs. $\mathrm{Ag} / \mathrm{AgCl}$ at $\mathrm{pH}$ 6.6). The insertion of nickel ions into $\mathrm{CN}_{\mathrm{x}}$ is further resulted in a strong quenching of the emission properties (Figure S9). Under illumination, nickel ions act as recombination centers which lead to non-radiative recombination paths as discuss later $^{43-44}$.

In order to understand the optical response of the $\mathrm{CN}_{\mathrm{x}}$ based photoanodes, it is necessary to research their light absorption capacity as a factor of the layer thickness, namely their absorption coefficient $(\alpha)$. As shown in Figure 4d, both CNx and Ni-CNs (3\%) exhibit acceptable $\alpha$ at short wavelength while $\mathrm{CN}_{\mathrm{x}}$ layer exhibits a sheer drop near its band gap energy at $490 \mathrm{~nm}$, while $3 \%$ $\mathrm{Ni}-\mathrm{CN}_{\mathrm{x}}$ presents a more gradual drop $(\lambda=667 \mathrm{~nm})$. Consequently, the Ni-CNs can harvest in efficient manner larger portion from the visible light compared to the pristine one. Another important consideration is related to the light penetration depth $\left(\alpha^{-1}\right)$, defined as the depth at which the light intensity falls to 1/e of the original value based on Beer-Lambert law. At $550 \mathrm{~nm}$, the penetration depth of $3 \% \mathrm{Ni}-\mathrm{CN}_{\mathrm{x}}, \mathrm{CN}_{\mathrm{x}}$ and $\mathrm{Si}$ are 385, 1345 and $1565 \mathrm{~nm}$, respectively. 
Taking account of light scattering, the film thickness is required to be at least 2.3 times the $\alpha^{-1}$

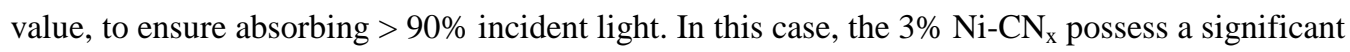
advantage in terms of impressively improving the utilization of photoanode material. By increasing the absorption coefficient $\alpha$ and diminishing the film thickness led to harvest $>90 \%$ of incident light, the material not only increases the incident light but also diminishes the percentage of charge carrier recombination when diffusing through the film.
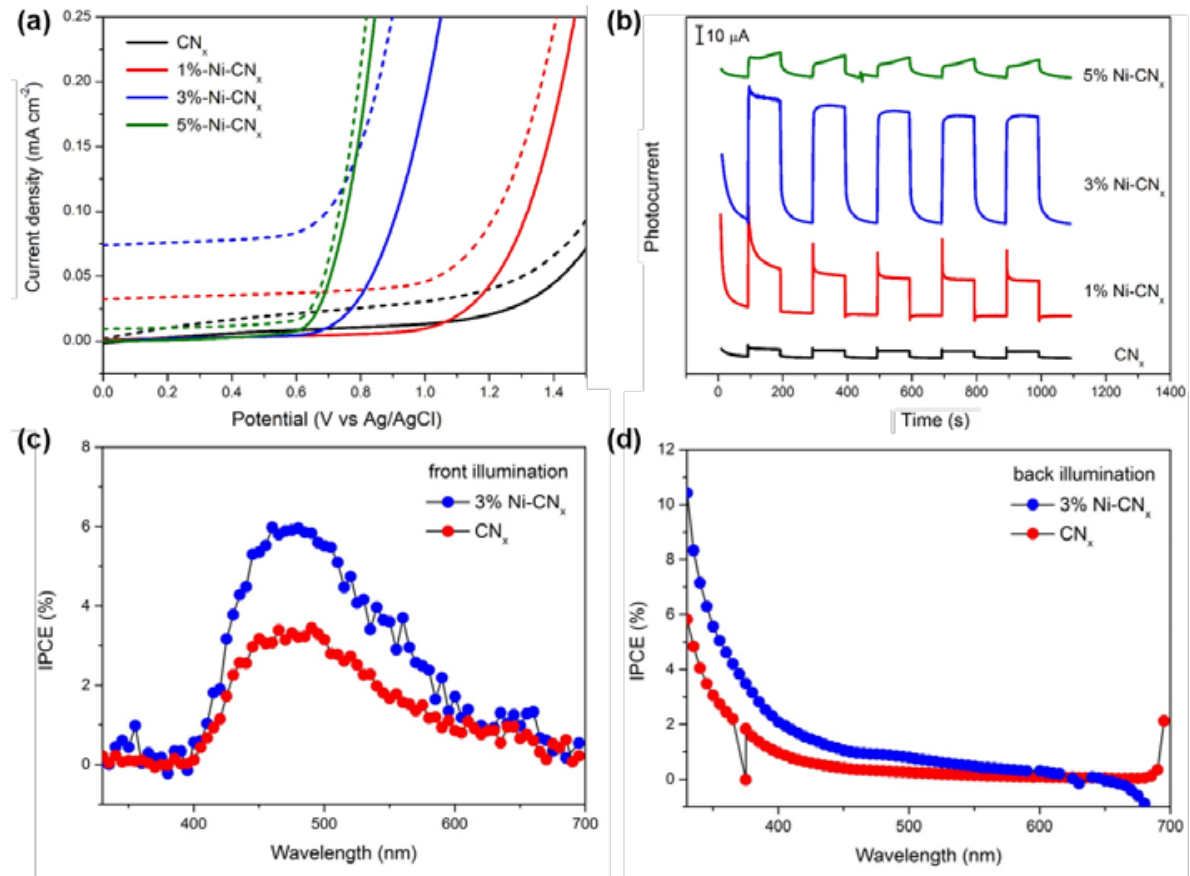

Figure 5. (a) Linear sweep voltammetry scans in the dark (solid curves) and under the AM 1.5 illumination (dash curves) for $\mathrm{CN}_{\mathrm{x}}$ and the $\mathrm{Ni}$ embedded $\mathrm{CN}_{\mathrm{x}}$ films; (b) The transient photocurrent density of $\mathrm{CN}_{\mathrm{x}}$ and the Ni embedded $\mathrm{CN}_{\mathrm{x}}$ films under $0.26 \mathrm{~V}$ versus $\mathrm{Ag} / \mathrm{AgCl}$ recorded under AM 1.5 front illumination; IPCE spectra for $\mathrm{CN}_{\mathrm{x}}$ and $3 \% \mathrm{Ni}-\mathrm{CN}_{\mathrm{x}}$ photoanodes under (c) frontside (d) backside illumination. 
The PEC properties of all the films were measured in $0.1 \mathrm{M} \mathrm{KOH}$ with a three-electrode electrochemical system, using a Pt wire as counter electrode and $\mathrm{Ag} / \mathrm{AgCl}$ as reference electrode. Linear sweep voltammetry scans (LSVs) were recorded in the dark and under AM 1.5 illumination for all photoanodes as shown in Figure 5a. The incorporation of nickel results in photocurrent enhancements as well as negative shift of the overpotential. All the modified films exhibit an early onset potential for oxygen evolution reactions thanks to the catalytic activity of $\mathrm{Ni}$ in alkaline solution. Considering that the major bottleneck of $\mathrm{CN}_{\mathrm{x}}$ in PEC is their poor catalytic nature for water oxidation, we found the in situ formed nickel species can efficiently improve water oxidation kinetics. However, when the nickel content arises to 5\%, the corresponding photocurrent is largely masked by the high electrocatalytic current. Figure S10 shows that with increasing nickel amounts, the electrocatalytic current (dark current) inclines due to the high activity of $\mathrm{Ni}$ as electrocatalyst. Meanwhile, the photocurrent densities increased from 5.6 for the pure $\mathrm{CN}_{\mathrm{x}}$ films to $22.3,69.8$ and $12.8 \mu \mathrm{A} / \mathrm{cm}^{2}$ at $0.26 \mathrm{~V} v$ s. $\mathrm{Ag} / \mathrm{AgCl}$ with $1 \%$, $3 \%$ and $5 \%$ of $\mathrm{Ni}$, respectively (Figure $5 \mathrm{~b}$ ). Another important parameter is the Ni oxidation state, as higher oxidation states facilitate oxygen evolution reaction. In accordance with the XANS data, the $\mathrm{Ni}^{3+}$ promote the best catalytic performance. Having all data in hand we conclude that the optimal molar ratio of nickel is $3 \%$. It is also important to note that the photoinduced onset for $3 \% \mathrm{Ni}^{-\mathrm{CN}_{\mathrm{x}}}$ shows a slight shift from $0.79 \mathrm{~V}$ (vs. Ag/AgCl) to $0.71 \mathrm{~V}$, compared to the dark measurement. Such a phenomenon can be attributed to the facile transfer of photogenerated holes to the nickel catalysts and to the electrolyte. The improved charge separation across the semiconductor/electrolyte interface suppresses the electron-hole recombination and may promoted the formation of hydroperoxide(OOH) species (key intermediates in the OER). Figure S11 shows the LSV of all films after stability measurement at 
constant photocurrent at $0.26 \mathrm{~V}$ versus $\mathrm{Ag} / \mathrm{AgCl}$ for $1200 \mathrm{sec}$. The results show that the activity is preserved, speaking for the good stability of the materials under working condition. To further study the charge carrier-transfer processes, electrochemical impedance spectroscopy (EIS) has been conducted (Figure S12 and Table S3). The decreased charge transfer resistance $\left(\mathrm{R}_{\mathrm{ct}}\right)$ values reveals that the charge transfer and transport resistance are significantly reduced with the increase of nickel in the final material.

To further assess the actual photoresponse of $\mathrm{CN}_{\mathrm{x}}$ and $3 \% \mathrm{Ni}-\mathrm{CN}_{\mathrm{x}}$, we performed incidentphoton-to-current efficiency (IPCE) measurements for front- and back-side illumination at 0.26 $\mathrm{V}$ (vs. $\mathrm{Ag} / \mathrm{AgCl}$ ) as shown in Figure $5 \mathrm{c}$ and $5 \mathrm{~d}$. Compared to the pristine $\mathrm{CN}_{\mathrm{x}}$ with an IPCE value of $1.5-3.4 \%$ around $450-550 \mathrm{~nm}$ under front illumination, the $3 \% \mathrm{Ni}-\mathrm{CN}_{\mathrm{x}}$ photoanode showed an enhanced IPCE values of 4-6\% in the same wavelengths range. Associated with the XPS depth results, this observation originates from the gradient distribution in $\mathrm{sp}^{2}$ bonded $\mathrm{C}$ of $3 \% \mathrm{Ni}-\mathrm{CN}_{\mathrm{x}}$ film, which in turn extends a gradient distribution of electric conductivity and conduction band gradient. The latter directs the electrons flow toward the conductive substrate and improves the carrier separation efficiency across the layer. On the other hand, nickel species play a critical role in assign the resistance to a higher superficial contact area at the semiconductor/electrolyte interface as well as a passivation of the superficial trap sites. However, limited by low solar energy density in the UV range, the inadequate light penetration depth and the excessive film thickness, lead to a decrease of IPCE values below 450 nm. For backside illumination, the carrier is generated near FTO/semiconductor interface. Therefore, electrons could be speedily collected while holes need to travel along the layer to reach the semiconductor/electrolyte interface. The profile changes between the back and front side 
illumination, strongly indicating that the $\sim 550 \mathrm{~nm}$ of $3 \% \mathrm{Ni}-\mathrm{CN}_{\mathrm{x}}$ layer is too thick and that the charges are recombined prior their collection (Figure 6).

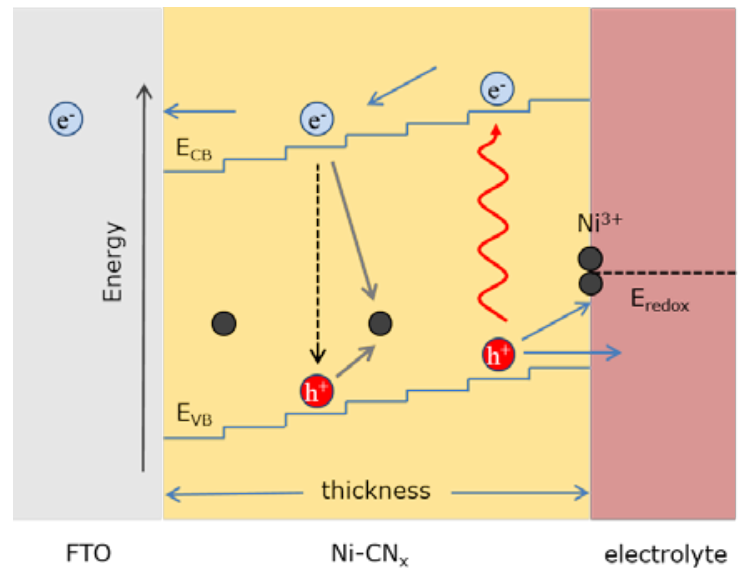

Figure 6. Schematic energy diagrams in the $3 \% \mathrm{Ni}-\mathrm{CN}_{\mathrm{x}}$ system under light excitation and the proposed charge transfer mechanism.

(a)

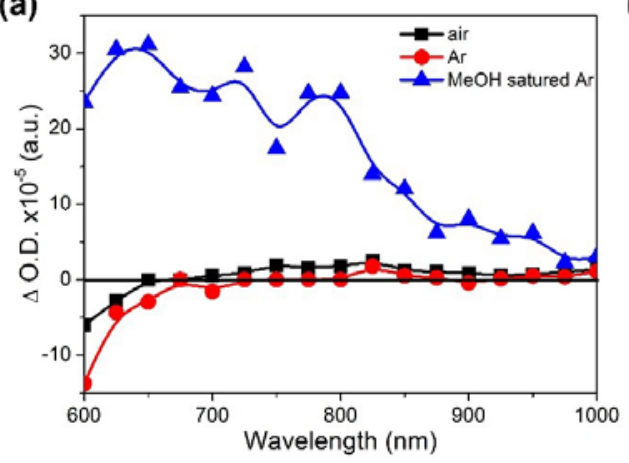

(b)

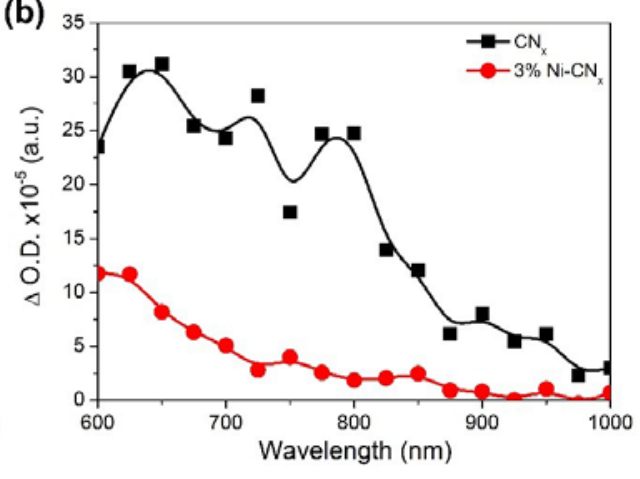


Figure 7. Transient absorption spectra of $\mathrm{CN}_{\mathrm{x}}$ films in air, $\mathrm{Ar}$ and $\mathrm{MeOH}$ saturated $\mathrm{Ar}$ atmospheres (a) and $\mathrm{CN}_{\mathrm{x}}$ and $3 \% \mathrm{Ni}-\mathrm{CN}_{\mathrm{x}}$ films in $\mathrm{MeOH}$ saturated $\mathrm{Ar}$ atmosphere (b). Excitation wavelength $532 \mathrm{~nm}$ and time acquisition $500 \mu \mathrm{s}$.

Transient absorption spectra of $\mathrm{CN}_{\mathrm{x}}$ and $3 \% \mathrm{Ni}-\mathrm{CN}_{\mathrm{x}}$ films were acquired at $500 \mu \mathrm{s}$ upon $532 \mathrm{~nm}$ excitation laser (Figure 7). As can be observed in Figure 7a, negligible transient signals were detected under $\mathrm{Ar}$ and air atmospheres from $\mathrm{CN}_{\mathrm{x}}$ and $3 \% \mathrm{Ni}-\mathrm{CN}_{\mathrm{x}}$ (not shown) thin films. However, under $\mathrm{MeOH}$ saturated Ar atmosphere a continuous transient absorption was observed in the sub-millisecond time scale. This type of continuous transient signals has been previously reported in semiconductor-like carbon-based materials and attributed to charge carriers. ${ }^{45-46}$ It is worthy to note that the oxygen present in the air atmosphere experiment, which is considered an efficient electron acceptor, have been found to quench $\mathrm{CN}_{\mathrm{x}}$ transient signal, while in $\mathrm{MeOH}$, a typically used hole scavenger, a strong transient absorption was recorded. Therefore, the observed transient signal can be attributed to photogenerated electrons in the $\mathrm{CN}_{\mathrm{x}}$ films, which in oxygen presence should be very short-lived, below the time resolution of our instrument but in the presence of a hole scavenger is long-lived ( $\mu$ s-ms time scale, Figure S14). The absence of $\mathrm{CN}_{\mathrm{x}}$ transient signal in $\mathrm{Ar}$ atmosphere indicates a fast electron-hole recombination reaction resulting in a shorter lifetime for charge separation than our instrument response $(1 \mu$ s). It is worthy to notice, that the absence of transient signal from the CNx sample when measured in $\mathrm{Ar}$ atmosphere, that is, without the presence of any electron or hole sacrificial agent, can be attributed to an electron-hole recombination faster than our instrument response (1 $\mu \mathrm{s})$.

Similarly, for the $3 \% \mathrm{Ni}-\mathrm{CN}_{\mathrm{x}}$, no transient signal was detected in the $\mu$ s time scale under Ar or $\mathrm{O}_{2}$. In contrast, in $\mathrm{MeOH}$ saturated Ar atmosphere a transient signal was detectable, although the signal intensity was clearly reduced compared with $\mathrm{CN}_{\mathrm{x}}$ sample (Figure $7 \mathrm{~b}$ ). This indicates that 
photogenerated electrons in the $\mathrm{CN}_{\mathrm{x}}$ there must be transferred to $\mathrm{Ni}^{+3}$ species, confirming their oxidizing behavior in the $\mathrm{Ni}-\mathrm{CN}_{\mathrm{x}}$ composites. Moreover, transient decays of photogenerated electrons in $\mathrm{MeOH}$ presented very different temporal profiles (Figure S14) in the range of $\mu \mathrm{s}-\mathrm{ms}$ time scale. In these temporal profiles, the transient signal obtained from the $3 \%-\mathrm{Ni}-\mathrm{CN}_{\mathrm{x}}$ sample presented a decay lifetime of $582 \mu$ s. On the contrary, the temporal profile recorded from the $\mathrm{CN}_{\mathrm{x}}$ sample presented a signal growth in the first $200 \mu \mathrm{s}$, and subsequent stationary signal up to $1 \mathrm{~ms}$. While, a lifetime of $582 \mu$ s was recorded for the $3 \%-\mathrm{Ni}-\mathrm{CN}_{\mathrm{x}}$ sample, the $\mathrm{CN}_{\mathrm{x}}$ sample showed a signal growth in the first $200 \mu \mathrm{s}$ and, then, the signal remaining stationary up to $1 \mathrm{~ms}$. This signal growth for $\mathrm{CN}_{\mathrm{x}}$ in the presence of $\mathrm{MeOH}$ could be attributed to the population of deep trap states from below the $\mathrm{CN}_{\mathrm{x}}$ conduction band, where electrons are found to be longlived (in me ms time scale). However, in the presence of $\mathrm{Ni}^{3+}$, these electrons are rapidly quenched, reducing their population and lifetime. Durrant et al. have recently reported a timeresolved spectroscopic study of charge trapping in aqueous carbon nitrides suspensions. They attributed a positive absorption feature, similar to shown in Figure 7, to photogenerated electrons in carbon nitride. These photoexcited electrons were found to get rapidly trapped $(<1$ ns) into an exponential tail of deep trap states (up to $1.5 \mathrm{eV}$ into the bandgap), promoting the accumulation of long-lived trapped electrons (seconds time scale). Moreover, deposition of $\mathrm{Pt}$ or $\mathrm{Ag}^{+}$on the carbon nitride resulted in transient amplitude decrease of up to 25\%, in good agreement with the amplitude quenching in the current study.

From the transient absorption spectra, comparing the behavior of $\mathrm{CN}_{\mathrm{x}}$ and $3 \% \mathrm{Ni}-\mathrm{CN}_{\mathrm{x}}$ in inert atmosphere, it can be concluded that electron-hole recombination in these materials is faster than our instrument response $(1 \mu)$. However, in both samples, holes can react with sacrificial electron donors, like $\mathrm{MeOH}$. Therefore, the transient signals observed have been assigned to electrons in 
both samples. However, the behavior of electrons in each sample has been found different suggesting different locations of the electrons. Secondly, electrons are much longer lived and unreactive in the absence of $\mathrm{Ni}$ ions ( $\mathrm{CN}_{\mathrm{x}}$ samnple), while they still decay and exhibit different spectrum when $\mathrm{Ni}$ ions are present therefore, improving the charge separation under working condition. Currently, there are several factors as insufficient charge carrier's transport and the thickness of the g-CN layer that still hinder the total efficiency. Nevertheless, there is ongoing research in our and other labs to improve the charge carrier transport ability and to understand the limiting factors of these photoanodes in order to enhance their performance in the future.

\section{Conclusion}

In summary, we showed a facile method to synthesize photoactive modified $\mathrm{CN}_{\mathrm{x}}$ films with oxygen evolution catalysts by using the interaction of Ni salts with molten organic molecule at elevated temperature prior the final material condensation. Our results show that the Ni ions are homogeneously disturbed within the g-CN layer forming an atomic metal doping within g-CN layer. The Ni amount was found as an effective tool to alter the g-CN band gap, photophysical, chemical and catalytic properties. We found that the best photoanode is based on 3\% Ni doping of the g-CN layer thanks to the in situ formation of the very active $\mathrm{Ni}^{3+}$ electrocatalyst and to the strong absorption enhancement in the visible region. Moreover, detailed XPS analysis combined with advance photophysical measurements indicate that the Ni ions were found to direct the gCN growth, leading to a band gap cascade which improves the charge separation processes under illumination. This work opens the opportunity for the growth of CN-based material with different metals and their corresponding ions by using their interaction in the monomer liquid-phase toward their implantation in photo and electronic devices. 
Supporting Information Available: Profilometer test and Cross section SEM images of CN $\mathrm{x}_{\mathrm{x}}, 3 \%$ Ni-CN ${ }_{\mathrm{X}}$ electrode; TEM, XRD, High-resolution XPS, XAS, Element analysis, PL spectra of the $\mathrm{CN}_{\mathrm{x}}$ and Ni modified $\mathrm{CN}_{\mathrm{x}}$ electrodes with different content; Transient photocurrent, Transient absorption decays of $\mathrm{CN}_{\mathrm{x}}$ and $3 \% \mathrm{Ni}-\mathrm{CN}_{\mathrm{x}}$; Expected modification of the idealized carbon nitride network by single-site nickels. This material is available free of charge via the Internet at http://pubs.acs.org.

\section{AUTHOR INFORMATION}

Corresponding Author

*Email: mennysh@bgu.ac.il, wangx@njust.edu.cn

\section{ACKNOWLEDGMENT}

We thank the Ilse Katz Institute for Nanoscale Science \& Technology Ben Gurion University for HR-TEM measurements.

\section{REFERENCES}

1. Bolton, J. R.; Strickler, S. J.; Connolly, J. S. Limiting and Realizable Efficiencies of Solar Photolysis of Water. Nature 1985, 316, 495.

2. Kamat, P. V.; Tvrdy, K.; Baker, D. R.; Radich, J. G. Beyond Photovoltaics: Semiconductor Nanoarchitectures for Liquid-Junction Solar Cells. Chem. Rev. 2010, 110, 66646688.

3. Sivula, K.; Van De Krol, R. Semiconducting Materials for Photoelectrochemical Energy Conversion. Nat. Rev. Mater. 2016, 1, 15010. 
4. Khan, S. U.; Al-Shahry, M.; Ingler, W. B. Efficient Photochemical Water Splitting by A Chemically Modified n-TiO 2 . Science 2002, 297, 2243-2245.

5. Yang, X.; Wolcott, A.; Wang, G.; Sobo, A.; Fitzmorris, R. C.; Qian, F.; Zhang, J. Z.; Li, Y. Nitrogen-Doped Zno Nanowire Arrays for Photoelectrochemical Water Splitting. Nano Lett. 2009, 9, 2331-2336.

6. Sivula, K.; Formal, F. L.; Grätzel, M. $\mathrm{WO}_{3}-\mathrm{Fe}_{2} \mathrm{O}_{3}$ Photoanodes for Water Splitting: A Host Scaffold, Guest Absorber Approach. Chem. Mater. 2009, 21, 2862-2867.

7. Cesar, I.; Kay, A.; Gonzalez Martinez, J. A.; Grätzel, M. Translucent Thin Film $\mathrm{Fe}_{2} \mathrm{O}_{3}$ Photoanodes for Efficient Water Splitting by Sunlight: Nanostructure-Directing Effect of SiDoping. J. Am. Chem. Soc. 2006, 128, 4582-4583.

8. Kim, T. W.; Choi, K.-S. Nanoporous $\mathrm{BiVO}_{4}$ Photoanodes with Dual-Layer Oxygen Evolution Catalysts for Solar Water Splitting. Science 2014, 343 (6174), 990-994.

9. Abe, R.; Higashi, M.; Domen, K. Facile Fabrication of an Efficient Oxynitride TaON Photoanode for Overall Water Splitting into $\mathrm{H}_{2}$ and $\mathrm{O}_{2}$ Under Visible Light Irradiation. J. Am. Chem. Soc. 2010, 132, 11828-11829.

10. Santra, P. K.; Kamat, P. V. Tandem-Layered Quantum Dot Solar Cells: Tuning The Photovoltaic Response with Luminescent Ternary Cadmium Chalcogenides. J. Am. Chem. Soc. 2013, 135, 877-885.

11. Park, J. H.; Kim, S.; Bard, A. J. Novel Carbon-Doped $\mathrm{TiO}_{2}$ Nanotube Arrays with High Aspect Ratios for Efficient Solar Water Splitting. Nano Lett. 2006, 6, 24-28. 
12. Wang, H.; Maiyalagan, T.; Wang, X. Review on Recent Progress in Nitrogen-Doped Graphene: Synthesis, Characterization, and Its Potential Applications. ACS Catal. 2012, 2 (5), 781-794.

13. Zhang, G.; Lan, Z. A.; Wang, X., Conjugated Polymers: Catalysts for Photocatalytic Hydrogen Evolution. Angew. Chem. Int. Ed. 2016, 55 (51), 15712-15727.

14. Zhang, G.; Lan, Z.-A.; Wang, X., The Surface Engineering of Graphitic Carbon Nitride Polymers with Cocatalysts for Photocatalytic Overall Water Splitting. Chem. Sci., 2017, DOI: 10.1039/C7SC01747B.

15. Yang, C.; Wang, B.; Zhang, L.; Yin, L.; Wang, X., Synthesis of Layered Carbonitrides from Biotic Molecules for Photoredox Transformations. Angew. Chem. Int. Ed. 2017, 56 (23), 6227-6231.

16. Zheng, Y.; Liu, J.; Liang, J.; Jaroniec, M.; Qiao, S. Z. Graphitic Carbon Nitride Materials: Controllable Synthesis and Applications in Fuel Cells and Photocatalysis. Energy Environ. Sci. 2012, 5, 6717-6731.

17. Martin, D. J.; Qiu, K.; Shevlin, S. A.; Handoko, A. D.; Chen, X.; Guo, Z.; Tang, J. Highly Efficient Photocatalytic H2 Evolution from Water Using Visible Light and StructureControlled Graphitic Carbon Nitride. Angew. Chem. Int. Ed. 2014, 53, 9240-9245.

18. Zhang, Y.; Thomas, A.; Antonietti, M.; Wang, X. Activation of Carbon Nitride Solids by Protonation: Morphology Changes, Enhanced Ionic Conductivity, and Photoconduction Experiments. J. Am. Chem. Soc. 2008, 131, 50-51. 
19. Zhang, Y.; Mori, T.; Ye, J.; Antonietti, M. Phosphorus-Doped Carbon Nitride Solid: Enhanced Electrical Conductivity and Photocurrent Generation. J. Am. Chem. Soc. 2010, 132, 6294-6295.

20. Ma, T. Y.; Ran, J.; Dai, S.; Jaroniec, M.; Qiao, S. Z. Phosphorus-D oped Graphitic Carbon Nitrides Grown in Situ on Carbon-Fiber Paper: Flexible and Reversible Oxygen Electrodes. Angew. Chem. Int. Ed. 2015, 54, 4646-4650.

21. Xu, J.; Cao, S.; Brenner, T.; Yang, X.; Yu, J.; Antonietti, M.; Shalom, M. Supramolecular Chemistry in Molten Sulfur: Preorganization Effects Leading to Marked Enhancement of Carbon Nitride Photoelectrochemistry. Adv. Funct. Mater. 2015, 25, 6265-6271.

22. Zhang, J.; Chen, Y.; Wang, X. Two-Dimensional Covalent Carbon Nitride Nanosheets: Synthesis, Functionalization, and Applications. Energy Environ. Sci. 2015, 8, 3092-3108.

23. Zhang, G.; Zang, S.; Wang, X. Layered $\mathrm{Co}(\mathrm{OH})_{2}$ Deposited Polymeric Carbon Nitrides for Photocatalytic Water Oxidation. ACS Catal. 2015, 5, 941-947.

24. Zhang, G.; Lan, Z.-A.; Lin, L.; Lin, S.; Wang, X. Overall Water Splitting by Pt/g-C $\mathrm{N}_{4}$ Photocatalysts Without Using Sacrificial Agents. Chem. Sci. 2016, 7, 3062-3066.

25. Shalom, M.; Inal, S.; Fettkenhauer, C.; Neher, D.; Antonietti, M. Improving Carbon Nitride Photocatalysis by Supramolecular Preorganization of Monomers. J. Am. Chem. Soc. 2013, 135 (19), 7118-7121. 
26. Shalom, M.; Guttentag, M.; Fettkenhauer, C.; Inal, S.; Neher, D.; Llobet, A.; Antonietti, M. In Situ Formation of Heterojunctions in Modified Graphitic Carbon Nitride: Synthesis and Noble Metal Free Photocatalysis. Chem. Mater. 2014, 26, 5812-5818.

27. Xu, J.; Antonietti, M.; Shalom, M. Moving Graphitic Carbon Nitride from Electrocatalysis and Photocatalysis to a Potential Electrode Material for Photoelectric Devices. Chem. Asian J. 2016, 11, 2499-2512.

28. Zhang, J.; Zhang, M.; Lin, L.; Wang, X. Sol Processing of Conjugated Carbon Nitride Powders for Thin-Film Fabrication. Angew. Chem. 2015, 127, 6395-6399.

29. Bian, J.; Xi, L.; Huang, C.; Lange, K. M.; Zhang, R. Q.; Shalom, M. Efficiency Enhancement of Carbon Nitride Photoelectrochemical Cells via Tailored Monomers Design. Adv. Energy Mater. 2016, 6, doi: 10.1002/aenm.201600263.

30. Xu, J.; Brenner, T. J.; Chabanne, L.; Neher, D.; Antonietti, M.; Shalom, M. Liquid-Based Growth of Polymeric Carbon Nitride Layers and Their Use in A Mesostructured Polymer Solar Cell with Voc Exceeding 1 V. J. Am. Chem. Soc. 2014, 136, 13486-13489.

31. Malara, F.; Minguzzi, A.; Marelli, M.; Morandi, S.; Psaro, R.; Dal Santo, V.; Naldoni, A. $\alpha-\mathrm{Fe}_{2} \mathrm{O}_{3} / \mathrm{NiOOH}$ : An Effective Heterostructure for Photoelectrochemical Water Oxidation. ACS Catal. 2015, 5, 5292-5300.

32. Zhang, G.; Huang, C.; Wang, X., Dispersing molecular cobalt in graphitic carbon nitride frameworks for photocatalytic water oxidation. Small 2015, 11 (9-10), 1215. 
33. Zhang, G.; Zang, S.; Lin, L.; Lan, Z. A.; Li, G.; Wang, X., Ultrafine Cobalt Catalysts on Covalent Carbon Nitride Frameworks for Oxygenic Photosynthesis. ACS Appl. Mater. Interfaces 2016, 8 (3), 2287.

34. Shalom, M.; Ressnig, D.; Yang, X.; Clavel, G.; Fellinger, T. P.; Antonietti, M. Nickel Nitride as an Efficient Electrocatalyst For Water Splitting. J. Mater. Chem. A 2015, 3, 81718177.

35. Zheng, Y.; Jiao, Y.; Zhu, Y.; Cai, Q.; Vasileff, A.; Li, L. H.; Han, Y.; Chen, Y.; Qiao, S.Z. Molecule-Level g- $\mathrm{C}_{3} \mathrm{~N}_{4}$ Coordinated Transition Metals as a New Class of Electrocatalysts for Oxygen Electrode Reactions. J. Am. Chem. Soc. 2017, 139, 3336-3339.

36. Lange, K. M.; Kothe, A.; Aziz, E. F. Chemistry in Solution: Recent Techniques and Applications Using Soft X-Ray Spectroscopy. PCCP 2012, 14, 5331-5338.

37. Lange, K. M.; Aziz, E. F. Electronic Structure of Ions and Molecules in Solution: A View from Modern Soft X-Ray Spectroscopies. Chem. Soc. Rev. 2013, 42, 6840-6859.

38. Khan, M.; Xiao, J.; Zhou, F.; Yablonskikh, M.; MacFarlane, D. R.; Spiccia, L.; Aziz, E. F. On the Origin of the Improvement of Electrodeposited MnOx Films in Water Oxidation Catalysis Induced by Heat Treatment. ChemSusChem 2015, 8, 1980-1985.

39. Khan, M.; Suljoti, E.; Singh, A.; Bonke, S. A.; Brandenburg, T.; Atak, K.; Golnak, R.; Spiccia, L.; Aziz, E. F. Electronic Structural Insights into Efficient $\mathrm{MnO}_{\mathrm{x}}$ Catalysts. J. Mater. Chem. A 2014, 2, 18199 -18203. 
40. Wang, H.; Butorin, S. M.; Young, A. T.; Guo, J. Nickel Oxidation States and Spin States of Bioinorganic Complexes from Nickel L-edge X-ray Absorption and Resonant Inelastic X-ray Scattering. J. Phys. Chem. C 2013, 117, 24767-24772.

41. Zhu, P.; Song, J.; Lv, D.; Wang, D.; Jaye, C.; Fischer, D. A.; Wu, T.; Chen, Y. Mechanism of Enhanced Carbon Cathode Performance by Nitrogen Doping in Lithium-Sulfur Battery: An X-ray Absorption Spectroscopic Study. J. Phys. Chem. C 2014, 118, 7765-7771.

42. Zhang, Y.; Antonietti, M., Photocurrent generation by polymeric carbon nitride solids: an initial step towards a novel photovoltaic system. Chemistry-An Asian Journal 2010, 5 (6), 13071311.

43. Zhang, J.; Chen, X.; Takanabe, K.; Maeda, K.; Domen, K.; Epping, J. D.; Fu, X.; Antonietti, M.; Wang, X., Synthesis of a carbon nitride structure for visible - light catalysis by copolymerization. Angew. Chem. Int. Ed. 2010, 49 (2), 441-444.

44. Zhang, J.; Zhang, G.; Chen, X.; Lin, S.; Möhlmann, L.; Dołęga, G.; Lipner, G.; Antonietti, M.; Blechert, S.; Wang, X., Co - Monomer Control of Carbon Nitride Semiconductors to Optimize Hydrogen Evolution with Visible Light. Angew. Chem. 2012, 124 (13), 3237-3241.

45. Baldoví, H. G.; Álvaro, M.; Ferrer, B.; García, H. Photoinduced Charge Separation on the Microsecond Timescale in Graphene Oxide and Reduced Graphene Oxide Suspensions.

ChemPhysChem 2016, 17, 958-962.

46. Baldoví, H. G.; Albarracín, F.; Álvaro, M.; Ferrer, B.; García, H. Influence of Dopant Loading on the Photo-and Electrochemical Properties of (N, O)- Co- Doped Graphene. ChemPhysChem 2015, 16, 2094-2098. 
TOC

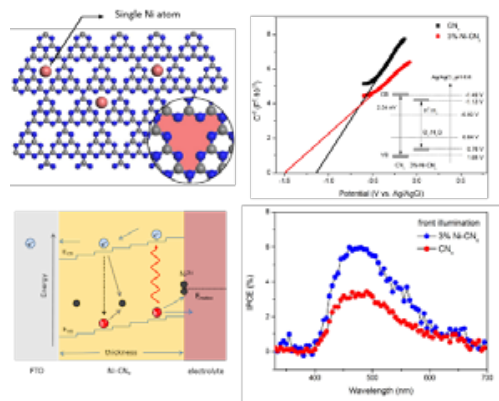

